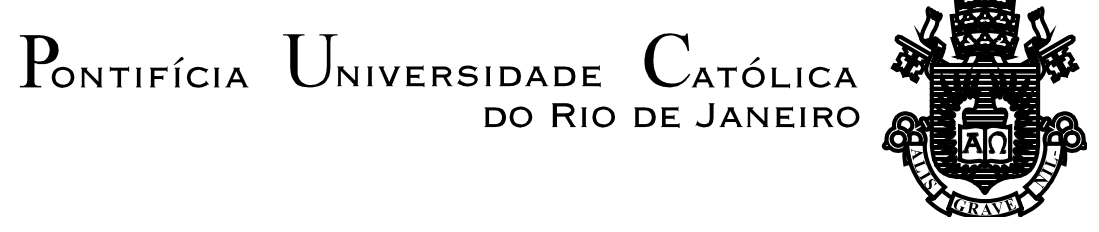

Lívia Miranda de Oliveira

\title{
A performance de pessoas com afasia na construção de narrativas em interações face a face em grupo
}

Tese de Doutorado

Tese apresentada como requisito parcial para obtenção do grau de Doutor pelo Programa de Pós-Graduação em Estudos da Linguagem do Departamento de Letras do Centro de Teologia e Ciências Humanas da PUC-Rio.

Orientador: Profa. Liliana Cabral Bastos 
Pontifícia Universidade $_{\text {Do Rio de Janeiro }}$

Lívia Miranda de Oliveira

\section{A performance de pessoas com afasia na construção de narrativas em interações face a face em grupo}

Tese apresentada como requisito parcial para obtenção do grau de Doutor pelo Programa de Pós-Graduação em Estudos da Linguagem do Departamento de Letras do Centro de Teologia e Ciências Humanas da PUC-Rio. Aprovada pela Comissão Examinadora abaixo assinada.

Profa. Liliana Cabral Bastos Orientadora Departamento de Letras - PUC-Rio

Profa. Maria do Carmo Leite de Oliveira Departamento de Letras - PUC-Rio

Profa. Ana Cristina Ostermann UNISINOS

Profa. Sonia Bittencourt Silveira UFJF

Profa. Erica de Araujo Brandão Couto UFMG

Profa. Denise Berruezo Portinari Coordenadora Setorial do Centro de Teologia e Ciências Humanas - PUC-Rio

Rio de Janeiro, 11 de março de 2013. 
Todos os direitos reservados. É proibida a reprodução total ou parcial do trabalho sem autorização da autora, da orientadora e da universidade.

\section{Lívia Miranda de Oliveira}

Graduada em Fonoaudiologia pela Universidade Federal do Rio de Janeiro em 2005. Mestre pelo Programa de Pós-graduação em Letras pela Universidade Federal de Juiz de Fora em 2008.

Ficha Catalográfica

Oliveira, Lívia Miranda de

A performance de pessoas com afasia na construção de narrativas em interações face a face em grupo / Lívia Miranda de Oliveira ; orientadora: Liliana Cabral Bastos. - 2013.

170 f. : il. (color.) ; $30 \mathrm{~cm}$

Tese (doutorado)-Pontifícia Universidade Católica do Rio de Janeiro, Departamento de Letras, 2013.

Inclui bibliografia

1. Letras - Teses. 2. Narrativa. 3. Performace. 4. Identidade. 5. Interação. 6. Afasia. I. Bastos, Liliana Cabral. II. Pontifícia Universidade Católica do Rio de Janeiro. Departamento de Letras. III. Título. 


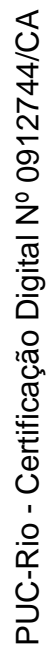

Aos meus pais 


\section{Agradecimentos}

Ao meu grande amor, meu Senhor e meu Deus, pois não me escolheu por ser capacitada, mas me capacitou por ser sua escolhida.

À Nossa Senhora, por sempre estar presente em minha vida, protegendome, orientando minhas escolhas e estando à frente de todos os acontecimentos.

Aos meus tão amados pais, Hugo e Raimunda, por muitas vezes abdicarem de si para lutarem pelas minhas realizações, que são deles também.

À minha querida e amada irmã e amiga, Mônika, por seguir de mãos dadas comigo, sendo a fonte das palavras verdadeiras que eu precisei escutar ao longo dessa caminhada acadêmica.

Ao companheiro que Deus escolheu para ser meu por toda minha vida, meu amado noivo, Leonardo, pelos incentivos nos últimos três anos desse trajeto e por entender minhas ausências.

À minha professora e orientadora, Liliana, por nortear minha pesquisa e pelas construções conjuntas no decorrer desses quatro anos, com as quais eu muito aprendi, como também, pelas inúmeras vezes em que foi colaborativa e incentivadora diante das minhas pretensões acadêmicas.

Às principais colaboradoras desta pesquisa, as participantes Carla, Laura e Tereza, sem as quais esta tese não seria uma realidade, e a quem serei eternamente grata.

Aos meus colegas do G-NIT, especialmente, à Dayse, à Debora e ao Julio, pela amizade tão necessária, por tantos momentos de compartilhamento de experiências e angústias acadêmicas, e pelas contribuições que enriqueceram minha pesquisa.

À professora Maria do Carmo, pelas contribuições substanciais e fundamentais à minha pesquisa, polidamente concedidas desde o exame de qualificação.

À minha professora e orientadora de mestrado, Sonia, por ter despertado em mim o encanto por essa vívida vertente de estudos linguísticos - a abordagem sócio-interacionista - e por ter me incentivado a ingressar no doutorado na PUCRio. 
Às professoras que compuseram a banca examinadora na defesa da minha tese, pela leitura atenciosa e cuidadosa do meu trabalho, bem como pelas relevantes e importantes contribuições concedidas de um modo bastante humano. Ao CNPq, pelo financiamento da minha pesquisa. 


\section{Resumo}

Oliveira, Lívia Miranda de; Bastos, Liliana Cabral. A performance de pessoas com afasia na construção de narrativas em interações face a face em grupo. Rio de Janeiro, 2013. 170p. Tese de Doutorado Departamento de Letras, Pontifícia Universidade Católica do Rio de Janeiro.

Inserida no quadro teórico-metodológico da Análise de Narrativa (cf. Riessman, 1993, 2008), esta pesquisa de natureza qualitativa e interpretativista tem o objetivo de investigar a performance de pessoas com afasia na construção de histórias de AVC, buscando compreender como se dá a construção colaborativa da narrativa e como as narradoras se constroem discursivamente, constroem o outro e as realidades que as cercam, diante (através) dos episódios de AVC por elas narrados. O alinhamento à concepção de linguagem como um sistema simbólico social e culturalmente construído (cf. Schiffrin, 1994), bem como a interface entre estudos de narrativa canônicos (cf. Labov e Waletzky, 1967; Labov, 1982) e interacionais (Sacks, [1968] 1992; Jefferson, 1978; Norrick, 2007; Garcez, 2001), no entendimento da narrativa como uma construção social, cultural e interacional, constituem o pano de fundo das análises empreendidas. Juntamente compondo o alicerce desta pesquisa, sobressaem estudos sobre performance e indentidade, orientando o entendimento de que narrar não se restringe a organizar eventos passados em uma ordem temporal e causal, mas, sobretudo, implica em construções identitárias e de relações com o outro (cf. Bruner, 1990; Bastos, 1999, 2004, 2005, 2008). Subsidiadas pelos referidos arcabouços teóricos e metodológicos, contando com o instrumental analítico do estudo de Ochs e Capps (2001) e com aproximadamente 15 horas de gravações em vídeo de interações face a face entre pessoas com e se afasia em grupo focal, das quais foram extraídas três narrativas de AVC para análise, nas investigações realizadas, foi possível observar: i) o engajamento ativo das narradoras afásicas no trabalho interacional de encaixe da narrativa na atividade discursiva circundante, bem como a colaboração substancial e indispensável da co-narradora não afásica nesse encaixe; ii) o turno a turno da estruturação das narrativas como um empreendimento inter-acional; iii) as ações das co-narradoras dando corpo à narrativa e possibilitando a manutenção da intersubjetividade da interação em curso; iv) a estruturação das histórias como narrativas que atendem aos requisitos 
de ordenação temporal e causal; v) a relevância do trabalho colaborativo na formatação da linearidade das narrativas; vi) a expertise altamente performática das narradoras afásicas na seleção de recursos utilizados na construção da historiabilidade; e vii) os modos distintos que as três narradoras elegeram para se construírem, construírem o outro e a realidade, diante dos episódios de AVC por elas narrados. Os resultados desta pesquisa iluminam que o encaixe da narrativa na atividade circundante, o envolvimento de múltiplos narradores na narração, a linearidade das histórias, a historiabilidade e a emergência de diferentes posturas morais consistem em negociações delegadas aos participantes da interação (narradores primários e co-narradores), ao invés de serem imposições a priori do contexto local (discursivo) e sociocultural, o que ressalta a tese de que narrativas são construções do aqui e agora da interação. Ademais, o fato de as narradoras apresentarem afasia coloca ainda mais em evidência o caráter inter-acional e colaborativo da narração, dada a frequente penetração das ações do outro no curso da construção da narrativa.

\section{Palavras-chave}

Narrativa; performance; identidade; interação; afasia. 


\section{Abstract}

Oliveira, Lívia Miranda de; Bastos, Liliana Cabral (Advisor). The performance of people with aphasia at narratives construction during face to face interactions in group. Rio de Janeiro, 2013. 170p. Doctoral Thesis - Departamento de Letras, Pontifícia Universidade Católica do Rio de Janeiro.

Once embedded in the Narrative Analysis' theoretical-methodological framework (cf. Riessman, 1993, 2008), the current qualitative and interpretative research aims to investigate performances from people with aphasia, regarding stroke stories construction, in order to understand how narratives are built in collaborative ways and how storytellers construct identities for themselves and the others, and how they build surrounding realities, throughout stroke episodes they have reported. The assumption of the concept of language as a social and cultural symbolic system (cf. Schiffrin, 1994), the interface between studies on canonic narratives (cf. Labov and Waletzky, 1967; Labov, 1982) and interactional ones (Sacks, [1968] 1992; Jefferson, 1978; Norrick, 2007; Garcez, 2001), and the sense of narratives as a social, cultural and interactional construction, constitute the background of the undertaken analysis. Along with it, comprising the basis of the current research, studies on performance and identity are highlighted, guiding one to the understanding that story telling is not an act restricted to organizing past events in a temporal and causal order, but, above all, it applies identity and relationship construction (cf. Bruner, 1990; Bastos, 1999, 2004, 2005, 2008). Subsidized by the mentioned theoretical and methodological framework, counting on Ochs and Capps analytical tools (2001) and on approximately 15 hours of face to face interaction video recordings from people with and without aphasia in focal groups, from which 3 stroke narratives were extracted to be analyzed, the investigation led to the possibility of seeing: i) the active engagement of storytellers with aphasia to the interactional means of to embed narratives in surrounding discursive activities; ii) the turn to turn of narrative formation as an interactional enterprise; iii) co-storytellers actions to "shape up" the report, making it possible to keep a maintenance process over the ongoing interaction's inter-subjectivity; iv) structuring stories as narratives that full fill temporal and causal organization requirements; v) the relevance of collaborative 
ways to the formation of narrative linearity; vi) storytellers with aphasia high performance expertise when selecting resources used to build tellability; and vii) distinct ways chosen by the three storytellers in order to construct themselves, others and reality, through stroke episodes they have reported. The current research outcomes show narratives embeddedness in surrounding discourse and social activity, the engagement of multiple storytellers to the narrative, linearity regarding stories, tellability and that different moral stances consist on interactional negotiations that participants are in charge of (primary storytellers and costorytellers), instead of being an a priori imposition of local (discursive) and sociocultural contexts. It highlights the theses that narratives are constructions related to here and now, throughout interaction processes. Besides, the fact that storytellers present aphasia underlines the interactional and collaborative features of storytelling, given the frequent penetration of somebody else's actions in the course of narrative constructions.

\section{Keywords}

Narrative; performance; identity; interaction; aphasia. 


\section{Sumário}

$\begin{array}{ll}\text { 1. Introdução } & 016\end{array}$

2. Estudos seminais clássicos sobre narrativas orais 022

2.1 O primeiro passo: a parceria entre Labov e Waletzky 022

2.2 Dando continuidade à primeira obra: o aprofundamento de 023 Labov

2.3 Compreendendo as contribuições dos estudos labovianos para 029 esta pesquisa

3. Diferentes modos de se olhar para uma narrativa: 032 contextualizações e posicionamento epistemológico

$\begin{array}{lll}3.1 & 0 & 032\end{array}$

$\begin{array}{lll}3.2 & 0 & 034\end{array}$

$\begin{array}{lll}3.3 & 0 \text { contexto sociointeracional } & 037\end{array}$

3.4 A proposta de uma abordagem híbrida como posicionamento 042 epistemológico desta pesquisa

$\begin{array}{lll}3.4 .1 & \text { Narração } & 046\end{array}$

$\begin{array}{lll}\text { 3.4.2 Historiabilidade } & 048\end{array}$

$\begin{array}{lll}3.4 .3 & \text { Encaixe } & 049\end{array}$

$\begin{array}{lll}3.4 .4 & \text { Linearidade } & 050\end{array}$

$\begin{array}{lll}\text { 3.4.5 Postura moral } & 051\end{array}$

4. Narrativa, identidade e performance 054

4.1 O processo de co-construção de identidades à luz de uma 054 abordagem socioconstrucionista

4.2 Visões de performance 
$\begin{array}{lll}\text { 4.2.1 O legado goffmaniano } & 060\end{array}$

$\begin{array}{lll}\text { 4.2.2 As contribuições de Bauman } & 065\end{array}$

4.2.3 Articulando as visões de Goffman e Bauman 068

$\begin{array}{lll}\text { 4.3 A relação narrativa versus identidade versus performance } & 070\end{array}$

$\begin{array}{lll}\text { 5. Pessoas com afasia em cena } & 074\end{array}$

$\begin{array}{lll}\text { 6. } & 079\end{array}$

$\begin{array}{lll}6.1 & \text { Pesquisa Qualitativa } & 079\end{array}$

6.2 Método de geração de dados: entrevista de grupo focal 080

6. 3 Método em Análise de Narrativa 086

6.3.1 Nível 1: Experiencialização do mundo 087

$\begin{array}{lll}\text { 6.3.2 Nível 2: Narração } & 089\end{array}$

$\begin{array}{lll}\text { 6.3.3 Nível 3: Transcrição } & 090\end{array}$

$\begin{array}{lll}\text { 6.3.4 Nível 4: Análise } & 091\end{array}$

$\begin{array}{lll}\text { 6.3.5 Nível 5: Leitura } & 093\end{array}$

$\begin{array}{lll}\text { 6. } 4 & \text { As participantes da pesquisa } & 094\end{array}$

$\begin{array}{lll}\text { 7. } & \text { Analise dos dados } & 099\end{array}$

7.1 Como se dá a construção colaborativa (e interacional) das 108 narrativas?

7.1.1 Como ocorre o trabalho interacional de encaixe das narrativas 108 na atividade discursiva em curso?

7.1.2 Quais as ações realizadas pelas co-narradoras que colaboram 118 na construção da narrativa?

7.1.3 Como a linearidade das narrativas é estruturada?

7.1.4 Quais recursos são utilizados pelas narradoras para 132 
construção da historiabilidade das narrativas?

7.1.5 Como as narradoras se constroem discursivamente, 143 constroem o outro e as realidades que as cercam, diante (através) dos episódios de AVC por elas narrados?

8. Considerações finais 151

$\begin{array}{lll}8.1 & \text { Resumo dos resultados } & 151\end{array}$

$\begin{array}{lll}8.2 & \text { Contribuições desta pesquisa } & 159\end{array}$

9. Referências 164

$\begin{array}{ll}\text { Anexo } & 170\end{array}$ 


\section{Lista de tabelas}

Tabela 1 - Dimensões da narrativa (Ochs \& Capps, 2001) 045

Tabela 2 - Comparação de abordagens mais e menos 084 estruturadas de grupo focal (Morgan, 2002)

Tabela 3 - Ações de encaixe da narrativa de Laura na atividade 111 discursiva em curso

Tabela 4 - Ações de encaixe da narrativa de Carla na atividade 114 discursiva em curso

Tabela 5 - Ações de encaixe da narrativa de Tereza na atividade 118 discursiva em curso

Tabela 6 - Ações realizadas pelas co-narradoras

Tabela 7 - Dispositivos avaliativos utilizados pelas participantes 142 afásicas

Tabela 8 - Resumo dos resultados 
Sei que os que confiam no Senhor Revigoram suas forças, suas forças se renovam Posso até cair ou vacilar, mas consigo levantar Pois recebo d'Ele asas E como águia, me preparo pra voar

Eu posso ir muito além de onde estou Vou nas asas do Senhor o Teu amor é o que me conduz. Posso voar e subir sem me cansar Ir pra frente sem me fatigar Vou com asas, como águia Pois confio no Senhor

Que me dá forças pra ser um vencedor Nas asas do Senhor Vou voar, voar

(Eros Biondini) 